\title{
Functional organization of the midbrain periaqueductal gray for regulating aversive memory formation
}

\author{
Li-Feng Yeh ${ }^{1,2 \dagger}$, Takaaki Ozawa ${ }^{3 \dagger}$ and Joshua P. Johansen ${ }^{1,2^{*}}$
}

\begin{abstract}
Innately aversive experiences produce rapid defensive responses and powerful emotional memories. The midbrain periaqueductal gray (PAG) drives defensive behaviors through projections to brainstem motor control centers, but the PAG has also been implicated in aversive learning, receives information from aversive-signaling sensory systems and sends ascending projections to the thalamus as well as other forebrain structures which could control learning and memory. Here we sought to identify PAG subregions and cell types which instruct memory formation in response to aversive events. We found that optogenetic inhibition of neurons in the dorsolateral subregion of the PAG (dIPAG), but not the ventrolateral PAG (VIPAG), during an aversive event reduced memory formation. Furthermore, inhibition of a specific population of thalamus projecting dIPAG neurons projecting to the anterior paraventricular thalamus (aPVT) reduced aversive learning, but had no effect on the expression of previously learned defensive behaviors. By contrast, inactivation of dIPAG neurons which project to the posterior PVT (pPVT) or centromedial intralaminar thalamic nucleus (CM) had no effect on learning. These results reveal specific subregions and cell types within PAG responsible for its learning related functions.
\end{abstract}

Keywords: Fear conditioning, Brainstem, Thalamus, Periaqueductal gray

\section{Introduction}

Innately aversive experiences produce immediate defensive behaviors and engage instructive circuits to trigger long lasting memories. The midbrain periaqueductal gray (PAG) coordinates defensive behavioral responses to innately and learned aversive events through afferent inputs from aversive sensory systems and forebrain regions like the amygdala and hypothalamus important for processing information related to learned and social threats [1-4]. For example, various forms of escape behavior are encoded in dorsolateral PAG (dlPAG)

\footnotetext{
*Correspondence: jjohans@brain.riken.jp

${ }^{\dagger}$ Li-Feng Yeh and Takaaki Ozawa have equally contributed to this work ${ }^{1}$ RIKEN Center for Brain Science, Laboratory for the Neural Circuitry of Learning and Memory, 2-1 Hirosawa, Wako-shi, Saitama 351-0198, Japan

Full list of author information is available at the end of the article
}

neurons [5-8] and stimulation of dlPAG produces escape behaviors $[7,9,10]$. Projections from hypothalamus to the dIPAG regulate escape responses from predators [11] while projections from the amygdala to PAG engage learned behavioral freezing and autonomic responses to sensory cues which have previously been associated with noxious stimuli [12]. The PAG then controls defensive motor and autonomic responses through projections to brainstem regions connected to the spinal cord and autonomic nervous system [10]. As suggested by the function of different afferent inputs from amygdala and hypothalamus to PAG, distinct PAG subregions regulate distinct types of defensive responses [1, 13]. In response to sensory cues that predict danger, the vlPAG engages passive defensive responses including freezing, bradycardia and analgesia, while the dIPAG controls active escape responses to threats. 
While the role of the PAG in producing innate and learned defensive responses is well established, some studies suggest that the PAG also participates in instructing learning in response to aversive stimuli during auditory fear conditioning [14-16]. During fear conditioning, animals learn that an innocuous auditory stimulus (conditioned stimulus or CS) predicts the occurrence of an aversive outcome (unconditioned stimulus or US, typically footshock) [17, 18]. Following learning, animals exhibit a variety of behavioral and autonomic responses upon presentation of the previously neutral auditory cue including behavioral freezing. Prior studies reported that PAG neurons receive synaptic input directly from the spinal cord dorsal horn and are shock responsive [14, 1921]. Furthermore, inactivation of PAG neurons reduces shock responsiveness in neuron in the lateral nucleus of the amygdala (LA) [14] where shock evoked depolarization is thought to produce synaptic plasticity underlying fear learning and memory [22-26]. Finally, stimulation of dlPAG, but not vlPAG, produces fear learning which is dependent on neural activity in the lateral amygdala [2, 15]. Although the PAG does not project directly to the LA, it has been hypothesized that PAG projections to the thalamus convey aversive instructive information to the LA and other forebrain structures to produce learning [27]. Together, this work suggests that the dIPAG is important for aversive associative learning, possibly through a population of PAG neurons which project to the thalamus. However, the PAG subregions and cell types which are necessary for producing aversive learning have not been identified. Furthermore, whether, and if so which, PAG projections to the thalamus are important in memory formation is not known.

\section{Results}

To determine which PAG subregions are important in fear learning, we used an optogenetic strategy to inhibit neurons in the vlPAG or dIPAG during the aversive shock period of auditory fear conditioning and examined the effects of these manipulations on auditory cue-evoked freezing responses, a behavioral measure of memory, $24 \mathrm{~h}$ later. Specifically, we injected adeno-associated virus expressing the hyperpolarizing archaerhodopsin $[28,29]$ or control vector (AAV5-CAG-ArchT-GFP or AAV5-CAG-GFP) into the vlPAG or dIPAG followed by implantation of fiber optic cables above the injection site

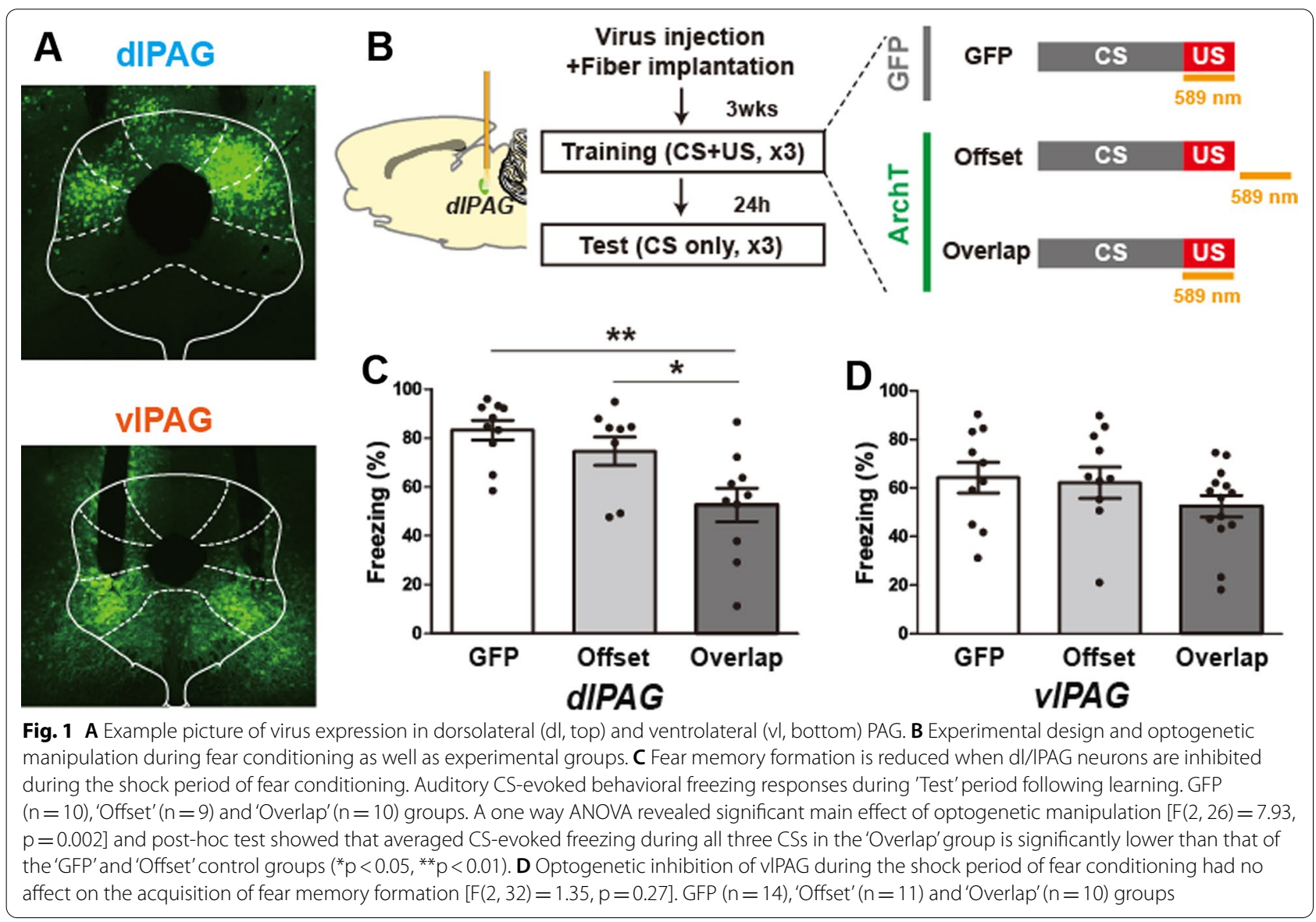


(Fig. 1A, B, Additional file 1: S1A). During the fear conditioning/training phase, we then attached the fiber optic cables to a laser and shone orange light to inhibit vlPAG or dIPAG neuronal activity during ('Overlap' group and a 'GFP' control group) or after (Offset group) the shock period of fear conditioning and examined the effects of these manipulations $24 \mathrm{~h}$ later at the memory test point (Fig. 1B). We found that inactivation of dlPAG, but not vlPAG, neurons reduced the acquisition of aversive memories in animals that received laser inhibition during the shock period of fear conditioning ('Overlap' group) relative to control animals (Fig. 1C, D).

Having identified a specific dIPAG subregion important for aversive learning, we next examined whether specific populations of dIPAG neurons which send axonal projection to thalamic regions are responsible for producing memory formation. We selected three midline thalamic nuclei, the anterior and posterior portions of the paraventricular nucleus (aPVT and pPVT) and the intralaminar centromedial nucleus (CM), as a previous study suggested that these regions receive input from the PAG [30] and also project to the LA [31-33]. The PAG projects to other midline thalamic nuclei including the centrolateral intralaminar nucleus, but these were not considered because they do not project to the LA. To test the anatomical connectivity between dIPAG and the aPVT, pPVT and CM using viral tracing approaches, we first injected a retrograde rabies virus [34] expressing archaerhodopsin-EYFP (eArchT3.0-EYFP) [35] into either aPVT, pPVT or CM and examined cell body labeling in the dIPAG. We found that injections into all of these regions produced moderate cell labeling in the dIPAG (Fig. 2A-C). While there was no significant difference in the number of EYFP + aPVT projecting compared with the number of pPVT projecting neurons, there was a significantly smaller number of cells projecting to CM compared with aPVT (Fig. 2D). We then injected an anterograde viral tracer (adeno-associated virus expressing EYFP) into dIPAG and identified substantial axonal labeling in all three thalamic regions (Fig. 2E-G). Thus, dIPAG neurons project substantially to all three midline thalamic nuclei.

We next examined whether activity in dIPAG neuron populations which project to one of these thalamic regions is necessary to produce aversive learning in response to shock. To test this we used an optogenetic approach to inactivate dIPAG neurons projecting to aPVT, pPVT or CM by injecting a retrograde rabies virus expressing eArchT3.0-EGFP into these thalamic regions in individual experiments, followed by implantation of fiber optic cables into the dlPAG (Fig. 3A). We then inactivated the thalamic projecting dlPAG neurons during the shock US period of auditory fear conditioning in separate experiments and compared this to animals which had received EGFP expressing virus ('GFP') or eArchT3.0EGFP with the 'Offset' treatment (Fig. 3A). We found that inactivation of aPVT, but not pPVT or CM, projecting dlPAG neurons reduced fear learning (Fig. 3B-D, Additional file 1: S1B-D). Furthermore, the number dlPAG neurons which were retrogradely labeled was significantly negatively correlated with the amount of freezing animals expressed $24 \mathrm{~h}$ after learning (i.e. higher expression of eArchT3.0 in dlPAG was correlated with reduced memory formation) in the aPVT $(\mathrm{r}=-0.64, \mathrm{p}=0.048)$, but not the CM $(\mathrm{r}=0.14, \mathrm{p}=0.38)$ or pPVT $(\mathrm{r}=-0.02$, $\mathrm{p}=0.49$ ), 'overlap' groups (Additional file 2: S2A-C). Importantly, inactivation of aPVT projecting dIPAG cells had no effect on the expression of previously learned freezing responses (Fig. 3E), demonstrating that this cell population does not participate in producing previously acquired learned freezing response. Next, to determine whether the aPVT projecting dlPAG cells are glutamatergic, we retrogradely tagged them (using the retrograde tracer Ctb647 injected into aPVT) and immunohistochemically labeled dIPAG cells with vGluT2, a marker of glutamatergic neurons. We found that aPVT projecting dIPAG neurons are almost exclusively glutamatergic (vGluT2 +, Additional file 2: S2D, E). Finally, to determine whether the aPVT projecting cells collateralize to CM or pPVT we injected $(n=3)$ a cocktail of two retrograde viruses, both expressing cre-recombinase (canine adenovirus, CAV-cre and retrograde traveling AAV, retroAAV-cre) followed by injection of a cre-dependent AAV virus expressing green fluorescent protein (AAVflex-GFP) into the dIPAG and examined the expression of axon collaterals in other regions. No axons were detected in CM or pPVT, but axons were seen consistently in other regions such as the dorsomedial hypothalamus $(\mathrm{DMH})$, cuneiform nucleus $(\mathrm{CnF})$ and parabrachial nucleus (PB) (Additional file 2: S2F, G). Together, these results show that a population of glutamatergic dIPAG neurons which project to the aPVT are important for fear memory formation, but not expression of previously learned fear responses.

\section{Discussion}

Together, these results demonstrate that during innately aversive experiences, activity in dlPAG, but not vlPAG, neurons is important for producing fear learning. Furthermore, these findings implicate a specific population of dIPAG glutamatergic neurons which project to the aPVT. While earlier studies reported that stimulation of dIPAG was sufficient to produce aversive learning [15, 16], the present findings demonstrate that activity in dIPAG cells during an aversive experience is necessary for aversive memory formation. 

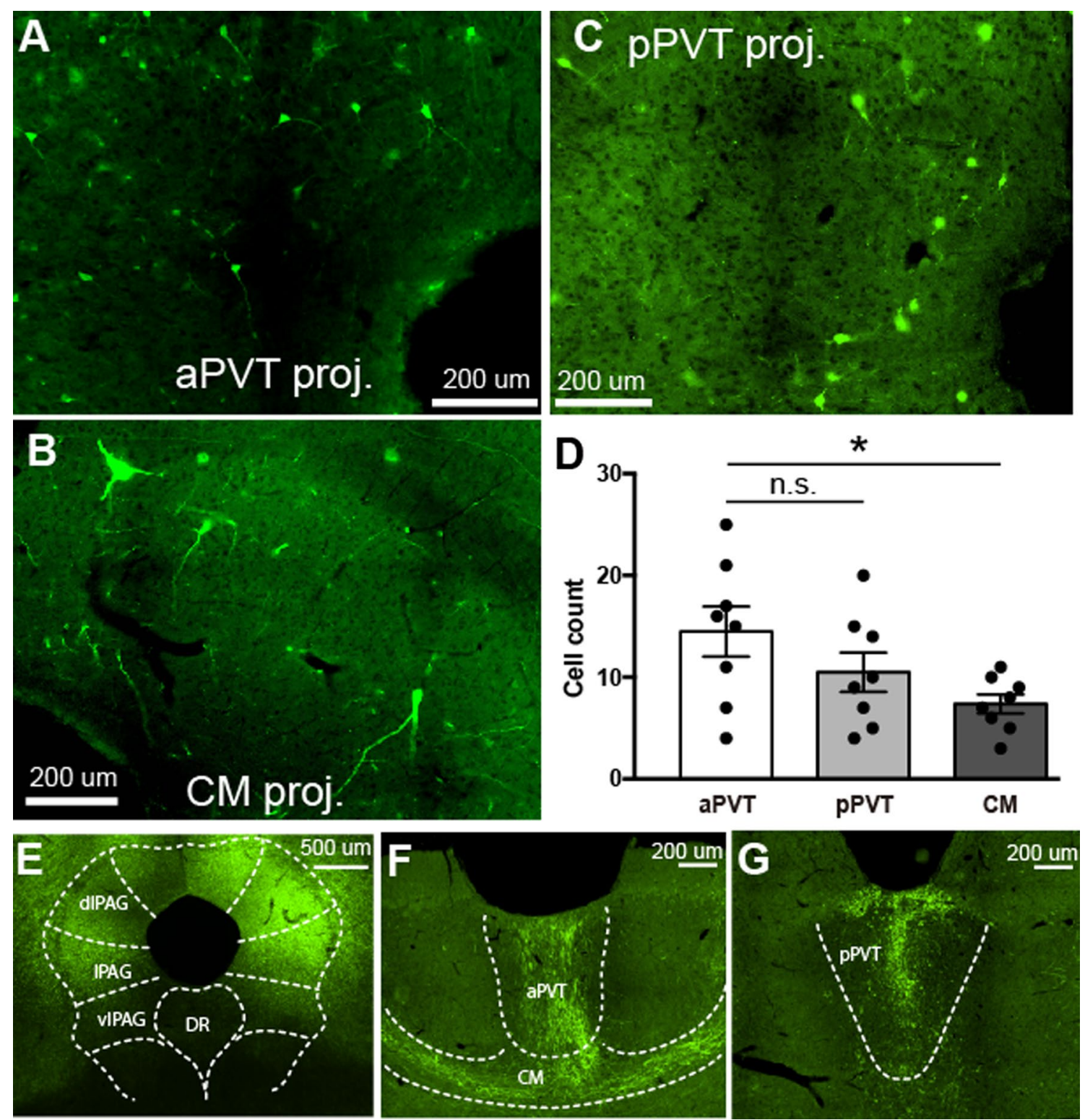

Fig. 2 A-C Example of retrogradely labeled dIPAG neurons projecting to the aPVT (A), CM (B) and PPVT (C). D, quantification of the number of dIPAG neurons labeled after injection of retrograde virus into aPVT $(n=8), \operatorname{PPVT}(n=8)$ and CM $(n=8)$. A one way ANOVA revealed a significant main effect of group $[F(2,21)=3.57, p=0.046]$ and post-hoc tests revealed no significant difference between the number of aPVT and pPVT projecting cells, but a significantly smaller number of CM compared with aPVT projecting dlPAG neurons $\left({ }^{*} \mathrm{p}<0.05\right)$. E-G Efferent axonal projections of dIPAG neurons to midline thalamic nuclei. E EYFP expression following virus injection into dIPAG. EYFP labeled axons in aPVT, CM (F) and pPVT (G) following virus injection into dIPAG

Our findings that dlPAG projections to aPVT support fear learning, while projections to pPVT do not, suggests that different afferent inputs can regulate distinct functions in these two PVT subregions. Previous experiments implicated the PVT in both aversive and reward processing [36-39]. Recent studies reported that distinct populations of aPVT cells projecting to different efferent targets facilitate aversive or reward learning and inhibit arousal while a class of genetically defined pPVT cells signal reward [40, 41]. Importantly, stimulation of PVT projections to the amygdala or ventral striatum produces place aversion [41]. While we found that aPVT projecting dIPAG neurons serve an aversive instructive function, it is unclear whether a dIPAG-aPVT-amygdala pathway is responsible for aversive learning. In fact, these aPVT projecting dIPAG cells also collateralize to other 

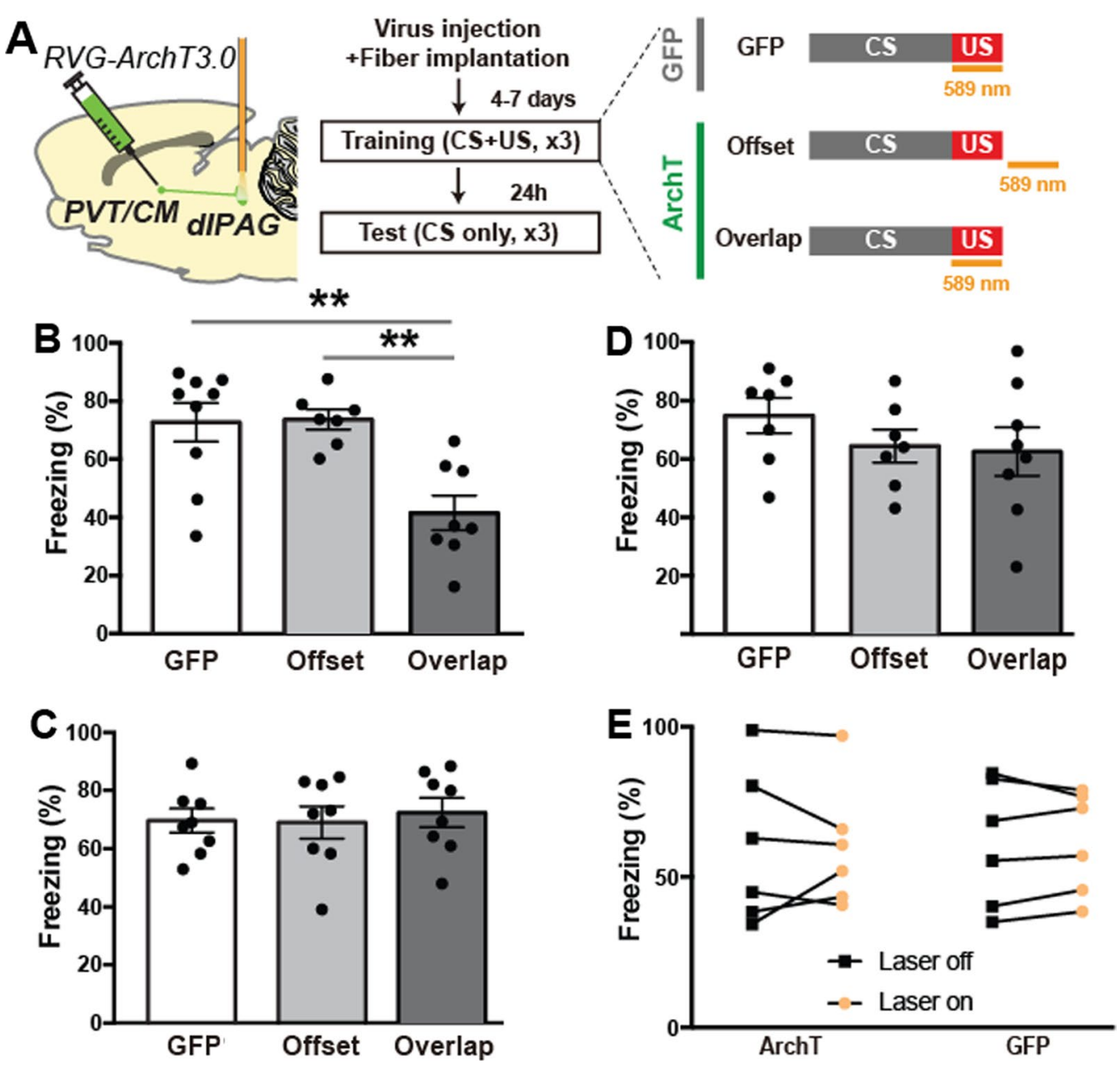

Fig. 3 A Experimental protocol for inactivation of PAG projection neurons during fear learning. $\mathbf{B}$ Inactivation of aPVT projecting dIPAG neurons reduced fear learning. A one way ANOVA revealed significant main effect of optogenetic manipulation $[F(2,21)=9.87, p=0.001]$ and post-hoc test showed that averaged CS-evoked freezing during the Test time-point in the 'Overlap' group $(n=8)$ was significantly lower than that of the 'GFP' $(n=9)$ and 'Offset' $(n=7)$ control groups ( $\left.{ }^{* *} p<0.01\right)$. C, $\mathbf{D}$ Inactivation of pPVT $(\mathbf{C},[F(2,21)=0.13, p=0.875] ; n=8$ for all groups) and CM (D, $[F(2,19)=0.92, p=0.417]$; Overlap $n=8$, Offset $n=7$, GFP $n=7$ ) projecting dIPAG neurons had no effect on fear learning. $\mathbf{E}$ Inactivation of aPVT projecting dIPAG neurons during auditory CS presentation following learning had no effect on the expression of previously learned fear responses. 2-way ANOVA interaction $[F(1,21)=0.0009, p=0.9752], n=6$ for both groups

brain regions in the brainstem which could participate in aversive learning (Additional file 2: S2F, G). Further studies will be needed to determine whether synaptic inputs of dlPAG neurons to aPVT (and specific aPVT cell types which project to the LA) participate in aversive learning.

Although the the role of distinct PAG sub-regions in eliciting different types of defensive responses has been extensively studied, how PAG circuits regulate learning is not as well understood. Opioid receptor activation in vlPAG is known to limit the strength and specificity of learning [42], suggesting that it could be part of a negative feedback circuit which inhibits aversive processing when aversive outcomes are anticipated and thereby regulates learning. Relatedly, recent studies found that vlPAG neurons respond to and encode the value of auditory CSs and this information could be used as a negative feedback signal that is activated by cues that predict danger [14, 43, 44]. Furthermore, inputs from the CeA to vlPAG are necessary for auditory CSs to activate a specific population of vlPAG neurons projecting to pain modulatory sites in the brainstem to control the adaptive strength of fear learning in response to different intensities of aversive experience [43]. Consequently, inhibition of these brainstem projecting vlPAG neurons or all vlPAG neurons enhances the strength of aversive 
associative learning [43, 45]. The CeA-vlPAG negative feedback pathway ultimately does this by inhibiting shock processing in various brain regions involved in fear learning, including in amygdala and dIPAG neurons, when the shock is predicted by a well-trained auditory CS. This limits depolarization of LA pyramidal neurons and thereby restrains learning [43]. These results along with prior reports that stimulation of PAG neurons is sufficient to produce aversive learning $[15,16]$ and the present findings showing that neural activity in a specific population of dIPAG neurons during the shock is necessary to produce learning support a revised model of PAG function in instructive signaling. According to this model, dlPAG provides instructive signals to forebrain centers in response to aversive events to produce learning while vlPAG neurons are activated by cues predicting noxious stimulation to restrain learning and set memory strength proportional to the intensity of the aversive experience.

The PAG (and many other brainstem regions) is a sensorimotor structure, but how sensory and motor information is encoded and used by different PAG subregions and cell types to both control behavior and initiate learning is not known. One possibility is that aversive sensory information is routed from PAG to the forebrain to inform the organism about innately aversive events in the external world to initiate emotional states and learning, while defensive motor information is encoded in PAG neurons projecting to brainstem motor structures. Alternatively, both sensory and motor information may be encoded in and conveyed to brainstem and forebrain structures. In this scenario, forebrain projecting dIPAG neurons may encode information about noxious stimuli and the escape responses these stimuli elicit. This could then be used by forebrain structures such as the amygdala to construct a representation of the external-sensory and internal-motor aspects of emotion inducing experiences which can drive learning. Answering this question is important as there is an old, but unresolved debate about whether emotional states represent sensory or motor aspects of emotion inducing experiences [46, 47]. One possibility is that dIPAG neurons projecting to brainstem motor regions initiate escape responses during aversive experiences (e.g. pain, visually threatening stimuli, etc.) while ascending dlPAG cells convey information about sensory and motor aspects of these experiences to produce emotional representations in forebrain structures which function to instruct learning as well as modulate and further coordinate ongoing behavioral responses. Answering this question may provide insights into how brainstem sensorimotor structures like the PAG support emotional state encoding in forebrain structures to regulate learning and behavior.

\section{Methods}

\section{Subjects}

Male Sprague-Dawley rats weighing 250-275 g were singly housed on a $12 \mathrm{~h}$ light/dark cycle and given food and water ad libitum. Experimental procedures were approved by the Animal Care and Use Committees of the RIKEN Brain Science Institute.

\section{Plasmids and viral vectors}

AAV5-hSyn-EYFP, AAV5-CAG-ArchT-GFP and AAV5CAG-GFP were produced and packaged by the University of North Carolina Vector Core. CAV2-cre was produced and packaged at Montpellier Vectorology. retroAAV2-Ubiq-mCRE virus as well as Rabies virus [34] (RV $\Delta$ G)-eArchT3.0-EGFP and RV $\Delta$ G-EGFP were produced and packaged in the Johansen laboratory.

\section{Stereotaxic cannula implantation and virus injection}

For all surgeries, animals were injected intraperitoneally with a mixture of ketamine $(100 \mathrm{mg} / \mathrm{kg})$ and Xylazine $(10 \mathrm{mg} / \mathrm{kg})$ and supplemental doses were given as required. For behavioral experiments where the vlPAG and dl/lPAG cell bodies or specific thalamic projecting dIPAG cells were optogenetically manipulated, following anesthesia, animals were placed in a stereotaxic frame (Leica or David Kopf Instruments) and stainless steel injection cannulae (26 gauge, Plastics One) attached to syringes (catalog $\# 80100$, Hamilton) through polyethylene tubing were targeted bilaterally (unilaterally for retrograde tracer) to dIPAG (AP: -7.2 , DV: $-5.4, \mathrm{ML}:+-0.8$ ) or vlPAG (AP: -7.5 , DV: -6.2 , ML: +-0.8 ). For rabies viral or retrograde tracer (alexa 647 conjugated cholera toxin subunit B (Ctb-647) Invitrogen) injections ( $0.3 \mathrm{ul}$ for both virus and tracer) into three different thalamic nuclei for manipulating or labeling thalamic projecting dIPAG neurons, the coordinates were as follows (aPVT: AP: $-1.8, \mathrm{DV}:-5.2$, ML: +-1.9 at 20 degree angle, pPVT: AP: -3.2 , DV: -5.2 , ML: +-1.9 at a 20 degree angle, CM: AP: -2.6 , DV: $-6.4, \mathrm{ML}:+-1.13$ at 10 degree angle). Retrograde tracers (viral or $\mathrm{Ctb}$ ) were delivered unilaterally into the aPVT. After a $2 \mathrm{~min}$ wait period, injections $(0.07 \mathrm{ul} / \mathrm{min}$ rate) were made and controlled by an automated pump (PHD2000, Harvard Apparatus), followed by a $15 \mathrm{~min}$ post-injection wait period. After injections were completed, bilateral optical cannulae (DFC_200/245_5.5mm DF1.6_FLT, Doric Lenses) were targeted to the dl/lPAG (AP: -7.2 , DV: -4.9 , ML: +-0.8 ) or vlPAG (AP: -7.5 , DV: -5.4 , ML: +-0.8$)$ and affixed to the skull using stainless steel surgical screws and dental cement. 


\section{Behavioral conditioning experiments}

For all auditory fear conditioning in behavioral studies, animals were placed into a sound isolating chamber (Med Associates) and received pairings of an auditory conditioned stimulus (CS) and electric shock unconditioned stimulus (US) during the training period. The CS for all experiments was a series of $85 \mathrm{db}, 5-\mathrm{kHz}$ tone pips (at $1 \mathrm{~Hz}$ with $250 \mathrm{~ms}$ on and $750 \mathrm{~ms}$ off) for $20 \mathrm{~s}$, and the foot shock US $(0.7 \mathrm{~mA})$ was presented concurrent with the final pip and lasted for $1 \mathrm{~s}$. Presentation of both CS and US were controlled by custom made software (MEDPC, Med Associates). For the optogenetic manipulation, we checked that the laser intensity was $15-20 \mathrm{~mW}$ from tips of optical fiber before each experiment.

For optogenetic cell body inactivation of dl or vlPAG experiments, 3 weeks after virus injection (AAV5-CAGArchT-GFP or AAV5-CAG-GFP) and optical cannula implant, animals were trained with 3 CS-US $(0.7 \mathrm{~mA})$ pairings. For optogenetic inactivation of thalamus projecting dlPAG neurons, training occurred 4-7 days following rabies virus injection. In all 'Overlap' and 'GFP' groups orange laser (589 $\mathrm{nm}$, Shanghai Laser) was provided to the target PAG area from $400 \mathrm{~ms}$ prior to US onset until $50 \mathrm{~ms}$ after US offset (total illumination time $=1.45 \mathrm{~s}$ ). In the 'Offset' group, laser was given 50-70 s (pseudorandomly) after each shock period. During a testing period $24 \mathrm{~h}$ after training, animals received 3 CS alone presentations with pseudorandom inter-trial intervals (2.5 min on average). Rats' freezing behavior during CS period during the test was scored using automated scoring software (Video Freeze, Med Associates). For experiments in which we inactivated aPVT projecting dIPAG neurons during expression of previously acquired fear responses, animals received 3 CS-US pairings. They then received $4 \mathrm{CS}$ retrieval trials $24 \mathrm{~h}$ after training. During two of the CSs, orange laser illumination began $400 \mathrm{~ms}$ before CS onset and ended $400 \mathrm{~ms}$ after CS offset (total of $20.8 \mathrm{~s}$ ) covered CS period (namely, 20 s). The presentation order of laser-CS and CS trials were counter-balanced across animals. The freezing level to laser-CS and CS without laser trials were averaged for each animal.

\section{Histological verification}

To verify transgene (ArchT-GFP, GFP) expression and location of optical fiber tips and cannulae in targeted brain areas, rats were overdosed (with a $25 \%$ chloral hydrate) and perfused and tissue sections were cut after each experiment as described previously (see previous description [22]). For vl/dlPAG manipulation experiments in Fig. 1, an experimenter blind as to animal and treatment group assessed whether transgene expression occurred specifically in these regions and whether the tip of the optical fibers were dorsal and proximal to the target area. For the manipulation of thalamic projecting dIPAG cells experiments, an experimenter blind as to animal and treatment group assessed whether thalamic injection cannulae tracks were centered in the target structure and whether there were retrogradely labeled neurons evident in the dlPAG. If these criteria were not met, animals were not included in the analysis. To quantify the retrograde rabies viral tracing (Fig. 2D), all animals from the 'Overlap' groups of all behavioral experiments were used for analysis and cells were counted from every 3 rd section from -6.8 to $-7.6 \mathrm{AP}$ from Bregma.

\section{Supplementary Information}

The online version contains supplementary material available at https://doi. org/10.1186/s13041-021-00844-0.

Additional file 1: Figure S1. A Locations of optical fiber tips to deliver laser into dIPAG (cyan dots) or vIPAG (orange dots). B-D Locations of optical fiber tips to deliver laser into dIPAG to manipulate aPVT (B), CM (C) and PPVT (D) projecting dIPAG neurons. Overlap $=$ cyan dots, Offset $=$ red dots, GFP $=$ green dots

Additional file 2: Figure S2: A-C Graphs showing correlations between the number of dIPAG cells retrogradely infected from aPVT (A), PPVT (B) and $C M(\mathbf{C})$ and the amount of tone evoked freezing following learning. D Example of retrogradely labeled dIPAG neurons projecting to the aPVT. Projections are labeled with Ctb 647 (white). E aPVT projecting dIPAG neurons are glutamatergic. Blue $=$ NeuN, Red $=$ vGluT2, White $=$ Ctb 647, overlay in upper left panel with triangles indicating triple labeled neurons F-G Axon collaterals labeled with GFP from aPVT projecting dIPAG neurons in the dorsomedial hypothalamus (DMH), cuneiform nucleus ( $\mathrm{CnF}$ ) and parabrachial nucleus (PB). scp = superior cerebellar peduncle, $3 \mathrm{~V}=$ 3rd ventricle.

\section{Acknowledgements}

We thank K. Conzelmann (Ludwig-Maximilians-University Munich) for the generous gift of the N,P, L and G pTIT-expressing plasmids52,53 and I. Wickersham (Massachusetts Institute of Technology) and J.A.T. Young (Salk Institute) for the generous gift of the BHK-B19G2 cell line used for rabies virus production.

\section{Authors' contributions}

LY and TO conceived of the project, carried out the experiments, analyzed data and helped draft the manuscript. JPJ conceived of the project and wrote the manuscript. All authors read and approved the final manuscript.

\section{Funding}

Funding was provided by RIKEN Center for Brain Science and the Japan Society for the Promotion of Science KAKENHI grant 25710003 to JPJ, $16 \mathrm{J10802}$ to $\mathrm{LY}$ and $19 \mathrm{H} 01769,21 \mathrm{H} 00311,21 \mathrm{~K} 18557$ to TO.

Availability of data and materials

Data will be made available upon reasonable request.

\section{Declarations}

Ethics approval and consent to participate Not applicable.

Consent for publication

Not applicable. 


\section{Competing interests}

The authors declare that they have no competing interests.

\section{Author details}

${ }^{1}$ RIKEN Center for Brain Science, Laboratory for the Neural Circuitry of Learning and Memory, 2-1 Hirosawa, Wako-shi, Saitama 351-0198, Japan. ${ }^{2}$ Department of Life Sciences, Graduate School of Arts and Sciences, University of Tokyo, 3-8-1 Komaba, Meguro-ku, Tokyo, 153-8902, Japan. ${ }^{3}$ Institute for Protein Research, Osaka University, 3-2 Yamadaoka, Suita-shi, Osaka 565-0871, Japan.

Received: 6 July 2021 Accepted: 23 August 2021

Published online: 08 September 2021

\section{References}

1. Gross CT, Canteras NS. The many paths to fear. Nat Rev Neurosci. 2012;13(9):651-8

2. Herry $C$, Johansen JP. Encoding of fear learning and memory in distributed neuronal circuits. Nat Neurosci. 2014;17(12):1644-54.

3. Bandler R, Price $J$, Keay KA. Brain mediation of active and passive emotional coping. Prog Brain Res. 2000;122:333-49.

4. Branco T, Redgrave P. The neural basis of escape behavior in vertebrates. Annu Rev Neurosci. 2020:43:417-39.

5. Deng $H$, Xiao X, Wang Z. Periaqueductal gray neuronal activities underlie different aspects of defensive behaviors. J Neurosci. 2016:36(29):7580-8.

6. Esteban Masferrer M, Silva BA, Nomoto K, Lima SQ, Gross CT. Differential encoding of predator fear in the ventromedial hypothalamus and periaqueductal grey. J Neurosci. 2020:40(48):9283-92.

7. Evans DA, Stempel AV, Vale R, Ruehle S, Lefler Y, Branco T. A synaptic threshold mechanism for computing escape decisions. Nature 2018;558(7711):590-4

8. Reis FM, Lee JY, Maesta-Pereira S, Schuette PJ, Chakerian M, Liu J, et al. Dorsal periaqueductal gray ensembles represent approach and avoidance states. Elife. 2021:6:10.

9. Vianna DM, Landeira-Fernandez J, Brandao ML. Dorsolateral and ventral regions of the periaqueductal gray matter are involved in distinct types of fear. Neurosci Biobehav Rev. 2001;25(7-8):711-9.

10. Tovote P, Esposito MS, Botta P, Chaudun F, Fadok JP, Markovic M, et al. Midbrain circuits for defensive behaviour. Nature. 2016:534(7606):206-12.

11. Wang W, Schuette PJ, Nagai J, Tobias BC, Cuccovia VRFM, Ji S, et al. Coordination of escape and spatial navigation circuits orchestrates versatile flight from threats. Neuron. 2021;109(11):1848-60 e8

12. Li H, Penzo MA, Taniquchi H, Kopec CD, Huang ZJ, Li B. Experiencedependent modification of a central amygdala fear circuit. Nat Neurosci. 2013:16(3):332-9.

13. Carrive P. The periaqueductal gray and defensive behavior: functional representation and neuronal organization. Behav Brain Res. 1993:58(1-2):27-47.

14. Johansen JP, Tarpley JW, LeDoux JE, Blair HT. Neural substrates for expectation-modulated fear learning in the amygdala and periaqueductal gray. Nat Neurosci. 2010;13(8):979-86.

15. Kim EJ, Horovitz O, Pellman BA, Tan LM, Li Q, Richter-Levin G, et al. Dorsal periaqueductal gray-amygdala pathway conveys both innate and learned fear responses in rats. Proc Natl Acad Sci USA. 2013;110(36):14795-800

16. Di Scala G, Mana MJ, Jacobs WJ, Phillips AG. Evidence of Pavlovian conditioned fear following electrical stimulation of the periaqueductal grey in the rat. Physiol Behav. 1987:40(1):55-63.

17. LeDoux JE. Emotion circuits in the brain. Annu Rev Neurosci. 2000;23:155-84

18. Lang PJ, Davis M. Emotion, motivation, and the brain: reflex foundations in animal and human research. Prog Brain Res. 2006;156:3-29.

19. Keay KA, Feil K, Gordon BD, Herbert H, Bandler R. Spinal afferents to functionally distinct periaqueductal gray columns in the rat: an anterograde and retrograde tracing study. J Comp Neurol. 1997:385(2):207-29.

20. Gauriau C, Bernard JF. A comparative reappraisal of projections from the superficial laminae of the dorsal horn in the rat: the forebrain. J Comp Neurol. 2004;468(1):24-56.

21. Heinricher MM, Cheng ZF, Fields HL. Evidence for two classes of nociceptive modulating neurons in the periaqueductal gray. J Neurosci. 1987;7(1):271-8.
22. Johansen JP, Diaz-Mataix L, Hamanaka H, Ozawa T, Ycu E, Koivumaa J, et al. Hebbian and neuromodulatory mechanisms interact to trigger associative memory formation. Proc Natl Acad Sci USA. 2014. https://doi.org/10.1073/ pnas.1421304111.

23. Johansen JP, Hamanaka H, Monfils MH, Behnia R, Deisseroth $\mathrm{K}$, Blair HT, et al. Optical activation of lateral amygdala pyramidal cells instructs associative fear learning. Proc Natl Acad Sci USA. 2010;107(28):12692-7.

24. Krabbe S, Grundemann J, Luthi A. Amygdala inhibitory circuits regulate associative fear conditioning. Biol Psychiatry. 2017. https://doi.org/10.1016/j. biopsych.2017.10.006

25. Wolff SB, Grundemann J, Tovote P, Krabbe S, Jacobson GA, Muller C, et al. Amygdala interneuron subtypes control fear learning through disinhibition. Nature. 2014;509(7501):453-8.

26. Rosenkranz JA, Grace AA. Dopamine-mediated modulation of odourevoked amygdala potentials during pavlovian conditioning. Nature 2002:417(6886):282-7.

27. McNally GP, Johansen JP, Blair HT. Placing prediction into the fear circuit. Trends Neurosci. 2011;34(6):283-92.

28. Han X, Chow BY, Zhou H, Klapoetke NC, Chuong A, Rajimehr R, et al. A high-light sensitivity optical neural silencer: development and application to optogenetic control of non-human primate cortex. Front Syst Neurosci. 2011:5:18.

29. Chow BY, Han X, Dobry AS, Qian X, Chuong AS, Li M, et al. High-performance genetically targetable optical neural silencing by light-driven proton pumps. Nature. 2010;463(7277):98-102.

30. Krout KE, Loewy AD. Periaqueductal gray matter projections to midline and intralaminar thalamic nuclei of the rat. J Comp Neurol. 2000:424(1):111-41.

31. Turner $\mathrm{BH}$, Herkenham M. Thalamoamygdaloid projections in the rat: a test of the amygdala's role in sensory processing. J Comp Neurol. 1991;313(2):295-325.

32. Vertes RP, Linley SB, Hoover WB. Limbic circuitry of the midline thalamus. Neurosci Biobehav Rev. 2015;54:89-107.

33. Li S, Kirouac GJ. Projections from the paraventricular nucleus of the thalamus to the forebrain, with special emphasis on the extended amygdala. J Comp Neurol. 2008;506(2):263-87.

34. Wickersham IR, Finke S, Conzelmann KK, Callaway EM. Retrograde neuronal tracing with a deletion-mutant rabies virus. Nat Methods. 2007;4(1):47-9.

35. Mattis J, Tye KM, Ferenczi EA, Ramakrishnan C, O'Shea DJ, Prakash R, et al. Principles for applying optogenetic tools derived from direct comparative analysis of microbial opsins. Nat Methods. 2012;9(2):159-72.

36. Millan EZ, Ong Z, McNally GP. Paraventricular thalamus: gateway to feeding, appetitive motivation, and drug addiction. Prog Brain Res. 2017;235:113-37.

37. Campus P, Covelo IR, Kim Y, Parsegian A, Kuhn BN, Lopez SA, et al. The paraventricular thalamus is a critical mediator of top-down control of cuemotivated behavior in rats. Elife. 2019. https://doi.org/10.7554/eLife.49041.

38. Do-Monte FH, Quinones-Laracuente K, Quirk GJ. A temporal shift in the circuits mediating retrieval of fear memory. Nature. 2015. https://doi.org/10. 1038/nature14030.

39. Penzo MA, Robert $\bigvee$, Tucciarone J, De Bundel D, Wang M, Van Aelst L, et al. The paraventricular thalamus controls a central amygdala fear circuit. Nature. 2015:519(7544):455-9.

40. Gao C, Leng Y, Ma J, Rooke V, Rodriguez-Gonzalez S, Ramakrishnan C, et al. Two genetically, anatomically and functionally distinct cell types segregate across anteroposterior axis of paraventricular thalamus. Nat Neurosci. 2020;23(2):217-28.

41. Do-Monte FH, Minier-Toribio A, Quinones-Laracuente K, Medina-Colon EM, Quirk GJ. Thalamic regulation of sucrose seeking during unexpected reward omission. Neuron. 2017:94(2):388-4004.

42. McNally GP, Cole S. Opioid receptors in the midbrain periaqueductal gray regulate prediction errors during pavlovian fear conditioning. Behav Neurosci. 2006;120(2):313-23.

43. Ozawa T, Ycu EA, Kumar A, Yeh LF, Ahmed T, Koivumaa J, et al. A feedback neura circuit for calibrating aversive memory strength. Nat Neurosci. 2017;20(1):90-7.

44. Wright KM, McDannald MA. Ventrolateral periaqueductal gray neurons prioritize threat probability over fear output. Elife. 2019. https://doi.org/10. 7554/elife.45013.

45. Assareh N, Bagley EE, Carrive P, McNally GP. Brief optogenetic inhibition of rat lateral or ventrolateral periaqueductal gray augments the acquisition of Pavlovian fear conditioning. Behav Neurosci. 2017;131(6):454-9. 
46. James W. The principles of psychology. New York: H. Holt and company; 1890.

47. Damasio A, Carvalho GB. The nature of feelings: evolutionary and neurobiological origins. Nat Rev Neurosci. 2013;14(2):143-52.

\section{Publisher's Note}

Springer Nature remains neutral with regard to jurisdictional claims in published maps and institutional affiliations.
Ready to submit your research? Choose BMC and benefit from:

- fast, convenient online submission

- thorough peer review by experienced researchers in your field

- rapid publication on acceptance

- support for research data, including large and complex data types

- gold Open Access which fosters wider collaboration and increased citations

- maximum visibility for your research: over $100 \mathrm{M}$ website views per year

At BMC, research is always in progress.

Learn more biomedcentral.com/submissions 